\title{
A Simple Elasto-Plastic Iterative Method by Fem for the Analysis of Plane Articulated Truss: Case of a 3-Bar Truss
}

\section{Djomi Rolland*, Fokam Bopda Christian, Kenmeugne Bienvenu, Kanmogne Abraham, Mbobda Gerard}

Laboratoire Engineering Civil et Mécanique, National Advanced School of Engineering (ENSPY/UY1), University of Yaounde 1, Yaoundé, Cameroon

Email: ^rdjomi@yahoo.fr

How to cite this paper: Rolland, D., Christian, F.B., Bienvenu, K., Abraham, K. and Gerard, M. (2021) A Simple Elasto-Plastic Iterative Method by Fem for the Analysis of Plane Articulated Truss: Case of a 3-Bar Truss. Journal of Materials Science and Chemical Engineering, 9, 12-23.

https://doi.org/10.4236/msce.2021.96002

Received: April 14, 2021

Accepted: June 26, 2021

Published: June 29, 2021

Copyright $\odot 2021$ by author(s) and Scientific Research Publishing Inc. This work is licensed under the Creative Commons Attribution International License (CC BY 4.0).

http://creativecommons.org/licenses/by/4.0/

\begin{abstract}
This paper presents a simplified numerical simulation tool for the elasto-plastic calculation of plane articulated truss by the finite element method (FEM) in MATLAB. The simplified approach consists of linearizing isotropic strain-hardening (to obtain a bilinear material law). The numerical implementation is built on the basis of the incremental and iterative FEM algorithms. The numerical resolution technique used is based on the projection methods of the modified Newton-Raphson solution. The MATLAB program is developed for the application of a 3-bar truss under monotonous quasi-static loading. Different values of the approximation error of the convergence criterion are used to study its impact on the quality of the algorithm. Numerical simulations have shown the reliability and quality of our simplified approach regardless of the approximation error.
\end{abstract}

\section{Keywords}

Articulated Truss, Elasto-Plastic, Newton-Raphson, Finite Element Method

\section{Introduction}

Structures consisting of truss elements are widely used in many engineering fields [1]. These trusses structures are fast to build, lightweight and allow large spans. The design of trusses structures has been the subject of numerous studies [2] [3] [4]. Many methods have been developed for the dimensioning of trusses. For small structures, classical analytical methods such as the node method (Culmann method) and the Ritter method are often used [5] [6]. For large structures, the graphical method was one of the first adopted techniques. 
As a result of the increasing performance of computers, finite element software is now widely used for the calculation of trusses. Using numerical simulation tools, some authors have worked on methods for structural optimization of trusses [7] [8] [9]. McKeown [7] presented a displacement optimization approach for the design of linear elastic trusses. The mechanical modeling of truss structures is simple under ordinary conditions to which the classical assumption of linear elasticity applies. However, modern applications of truss structures often require plasticity material analysis, which can accurately predict the structural responses. This observation is justified by structural failures, such as the collapse of the I-35W Bridge over the Mississippi River in Minneapolis [10] [11]. Fan and et al. [12] studied the static and dynamic elasto-plastic stability of crosslinked hulls, while Ferrari et al. [13] numerically studied the non-linear elasto-plastic response of the historical Pardermo truss bridge. All these approaches are strongly non-linear.

In the present work, we propose a numerical simulation approach by FEM for the plane articulated truss. Our modeling will be based on a linearized material law of isotropic plastic strain-hardening (linearization of the elasto-plastic behavioral law: bilinear law) and on a projection method using the modified Newton-Raphson approach.

\section{Simplified Behaviour Model}

\section{Selecting a Template}

In this study, we are interested in the elasto-plastic behaviour of articulated truss structures. A simplified linear isotropic strain-hardening model of the Johson Cook type [14] is implemented. Thus, the simplified model is bilinear and characterized by a Young's modulus $E$ and a tangent modulus $E_{T}$, the yield strength $\sigma_{0}$, yield stress projection $\sigma_{0}^{\prime}$ (see Figure 1 ). The material constituting our truss is made of a metal alloy, therefore the actual behaviour law is shown in Figure 1(a). The corresponding simplified model is shown in Figure 1(b). In this study, we do not consider the phenomena of damage and failure [15].

This approximation of the real material behaviour law (Figure $1(\mathrm{a})$ ) by a bilinear behaviour law of elasto-plastic type with linear strain hardening (Figure $1(\mathrm{~b})$ ) permits to write the following incremental plastic flow law (Equation (1)):

$$
d \sigma=E_{T} d \varepsilon
$$

With $d \varepsilon=d \varepsilon^{e}+d \varepsilon^{p}$,

$d \varepsilon^{e}$ : elastic deformation increment;

$d \varepsilon^{p}$ : plastic deformation increment.

We deduce the evolution law of linear strain-hardening (Equation (2)):

$$
\sigma=\sigma_{s}\left(\sigma_{0}, E\right)+H d \varepsilon_{p}
$$

With $H=\frac{E_{T}}{1-\frac{E_{T}}{E}}, H$ is called the strain-hardening modulus, $\left(\sigma_{0}, E\right):$ Current 


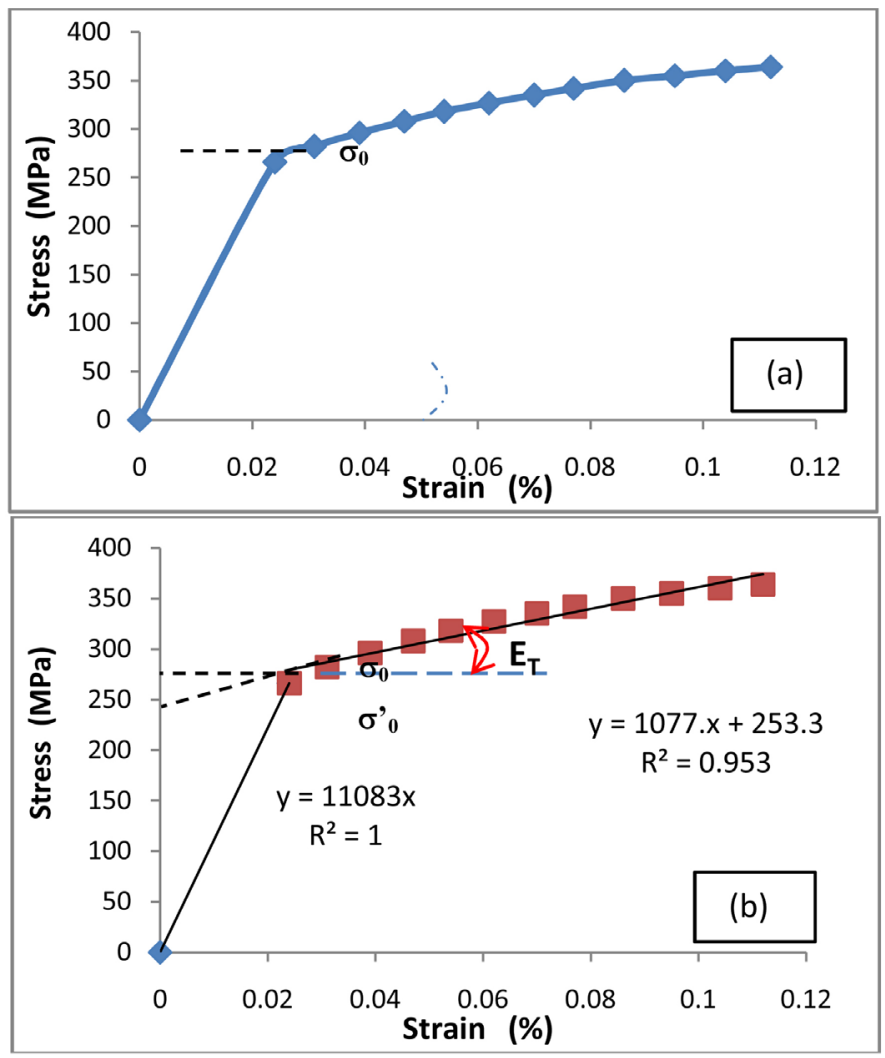

Figure 1. Tensile stress-strain curves. (a) Actual experimental curve,

(b) Linear approximation of strain-hardening (simplified model).

yield strength.

Equation (2) can also be expressed as a $\sigma_{0}^{\prime}$ function as follows (Equation (3)):

$$
\sigma=\sigma_{0}^{\prime}\left(\sigma_{0}, E\right)+E_{T} \varepsilon
$$

The linearized elasto-plastic evolution allows a simplified writing of the discretized elementary equilibrium, obtained analytically by the FEM an articulated truss (Equation (4)):

$$
(\underbrace{\int_{V}\left([B]^{\mathrm{T}} E_{T}[B] \mathrm{d} V\right)}_{\left[K_{e}\right]}\left\{\left\{q_{e}\right\}=[F]^{e}-\int_{V}[B]^{\mathrm{T}} \sigma_{0}^{\prime} \mathrm{d} V\right.
$$

$\left[K_{e}\right]$ : local stiffness matrix, $[B]$ : strain-displacement relationship matrix, $\left\{q_{e}\right\}$ : Nodal displacement field.

\section{Elasto-Plastic Numerical Resolution}

The numerical solving technique used in our elasto-plastic problem is based on the classical incremental, iterative approach and on the minimization of a convergence criterion. The modified Newton Raphson-type projection method, which uses the elastic stiffness matrix at each iteration. Figure 2 presents the algorithm followed in MATLAB program [2]. 


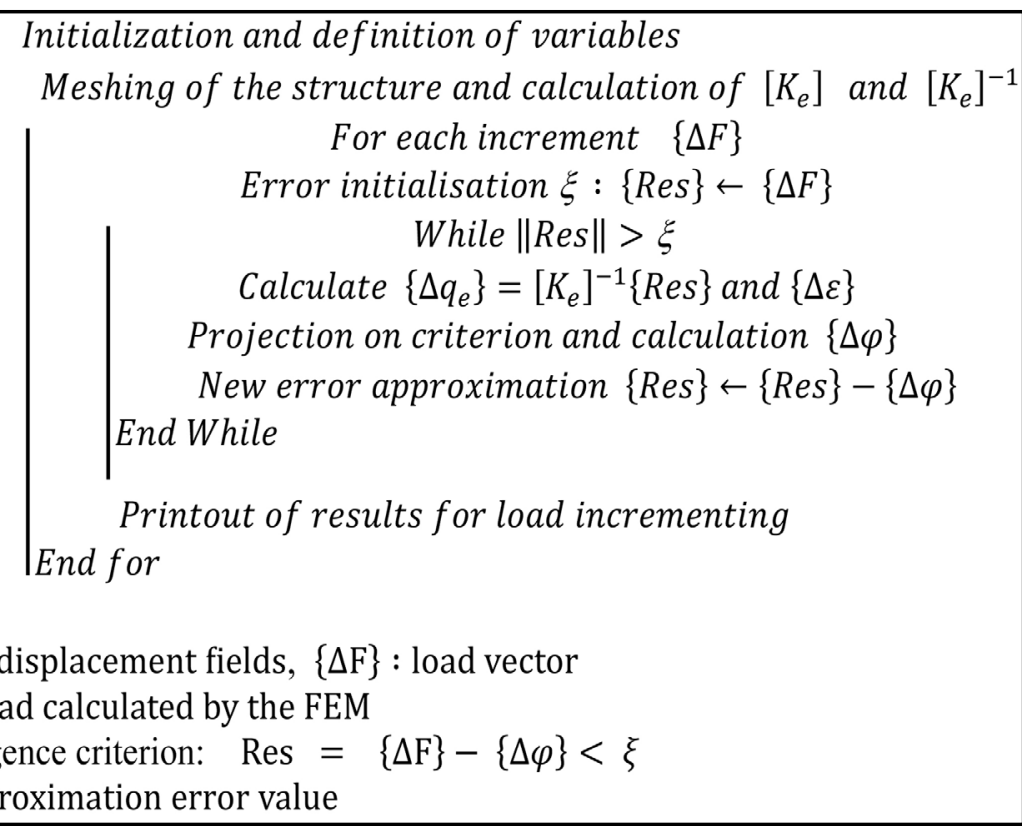

Figure 2. Summary of numerical resolution algorithm.

\section{Projection Method}

The projection method on the solution sought is the modified Newton-Raphson method. The linear approximation of the plasticity law allows an easy calculation of the hardening, thus saving the CPU processing time. Figure 3 shows the principle of projection on the boundary of the current elasticity domain for an increase in $d \varepsilon$ deformation. We have represented the most general case of an element being plasticized. We consider a history of initial stress equal to $\sigma$ and the state of current strain hardening is denoted $\sigma_{h}$.

The linear approximation of the strain hardening allows to obtain by a simple calculation, the plastic evolution law. From Figure 3(b), are geometrically deduced the relations presented in equations 5 to 8 . First, we define a quantity $R$, as follows (Equation (5)):

$$
R=\frac{A B}{A C}=\frac{\sigma+d \sigma_{e}-\sigma_{h}}{d \sigma_{e}}=1+\frac{\sigma-\sigma_{h}}{d \sigma_{e}}
$$

We deduce from the Figure 3(b) (Equation (6)):

$$
\begin{gathered}
X=R d \varepsilon \Rightarrow \\
\mid \begin{array}{l}
\text { Plastic slope } E_{T}=\frac{B \sigma^{\prime}}{X} \rightarrow B \sigma^{\prime}=R E_{T} d \varepsilon \\
B C=A C-A B \rightarrow B C=(1-R) d \sigma_{e}
\end{array}
\end{gathered}
$$

The law of evolution (Equation (7)):

$$
\sigma^{\prime}=\sigma+\underbrace{(1-R) E d \varepsilon+R E_{T} d \varepsilon}_{d \sigma}
$$

The increments of elastic and plastic deformations are deduced from the stress increment as follows (Equation (8)): 

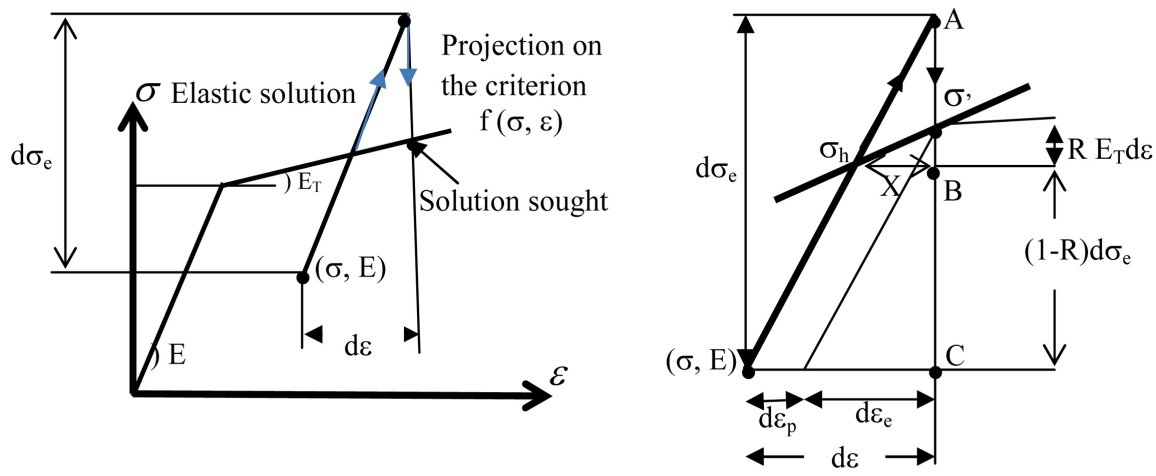

Figure 3. Representation of the projection method [2].

$$
\| \begin{aligned}
& \varepsilon_{e}=\frac{1}{E} d \sigma \rightarrow d \varepsilon_{e}=\left(1-R+R \frac{E_{T}}{E}\right) d \varepsilon \\
& d \varepsilon_{p}=d \varepsilon-d \varepsilon_{e} \rightarrow d \varepsilon_{p}=R\left(1-\frac{E_{T}}{E}\right) d \varepsilon
\end{aligned}
$$

The numerical implementation is done through the projection algorithm of Figure 4 .

\section{Case of Application}

The application case structure in this article is a truss consisting of three (03) bars of identical cross-section $S$ (see Figure 5). The inclined bar is of length $\sqrt{2} L$ and the other of length $L$. The material behaviour law described is the one presented in Section 2. The numerical values considered are: $L=500 \mathrm{~mm}$, Young's modulus $E=70.000 \mathrm{MPa}$, tangent modulus $E_{T}=510.8 \mathrm{MPa}$, yield strength $\sigma_{0}=281.559 \mathrm{MPa}$, bar section $\mathrm{S}=50 \mathrm{~mm}^{2}$. Table 1 shows the table of connectivities of the 3-bar truss structure.

The resolution by FEM involves either a matrix or a discrete formulation of the problem. In the displacement approach, the main unknowns of the problem are the nodal displacements of the structure. In this article, the stiffness matrix is used to construct the FEM model. The elementary stiffness matrix (for each bar element) is written. In the case of the articulated trusses we consider 1 nodal degree of freedom in the local reference and 2 nodal degrees of freedom in the global reference.

The global stiffness matrix is obtained after assembling the elementary stiffness matrices. Thus, the main unknown, which is the nodal displacement vector is calculated by solving the global matrix equilibrium equation $[K]\{Q\}=\{F\}$. In this equation, $[K]$ is the global stiffness matrix, $\{F\}$ the nodal force vector and $\{Q\}$ the nodal displacement vector. When the bar element is in the plastic behaviour phase, the local matrix equilibrium equation is modified as shown in Equation (4). Once the nodal displacement vector has been determined, the internal forces in the bars can be deduced. In the application case of 3-bar truss in this article, the global stiffness matrix is presented in Equation (9). A computational code is developed in MATLAB for the application case. 


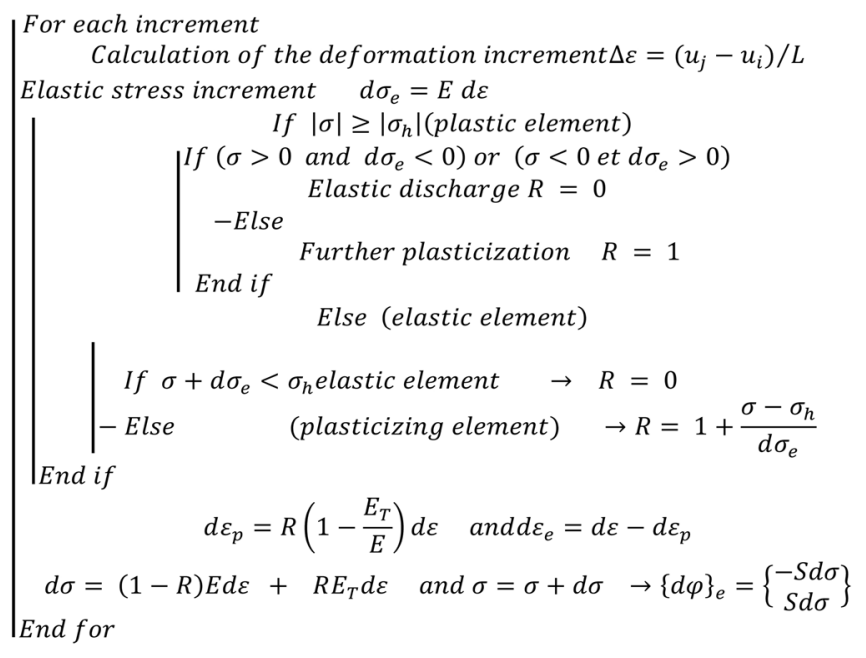

Figure 4. Projection algorithm (modified Newton-Raphson) [2].

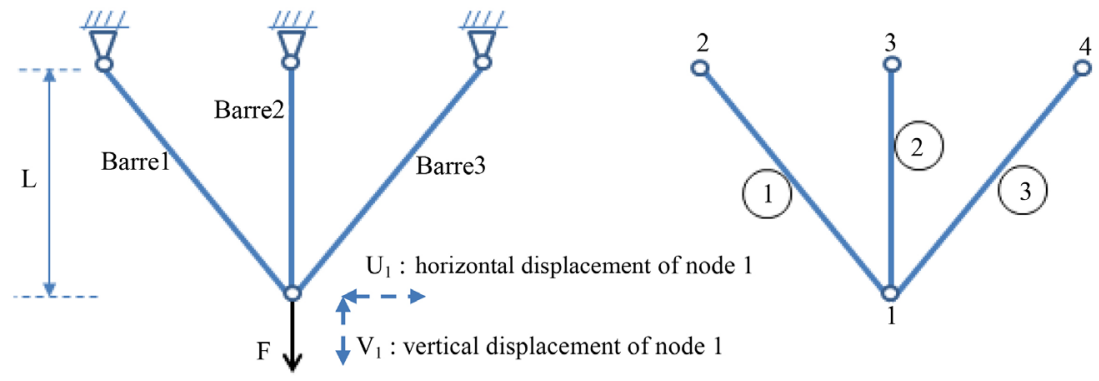

Figure 5. Truss structure studied.

Table 1. Table of connectivity.

\begin{tabular}{cccccc}
\hline Element & Node 1 & Node 2 & Length & Section & Inclination \\
\hline Bar 1 & 1 & 2 & $\sqrt{2} L$ & $\mathrm{~S}$ & $135^{\circ}$ \\
Bar 2 & 1 & 3 & $L$ & $\mathrm{~S}$ & $90^{\circ}$ \\
Bar 3 & 1 & 4 & $\sqrt{2} L$ & $\mathrm{~S}$ & $45^{\circ}$ \\
\hline
\end{tabular}

$$
[K]=\left[\begin{array}{ccccccccc}
\frac{E S}{2 L \sqrt{2}}+\frac{E S}{2 L \sqrt{2}} & 0 & -\frac{E S}{2 L \sqrt{2}} & \frac{E S}{2 L \sqrt{2}} & 0 & 0 & -\frac{E S}{2 L \sqrt{2}} & -\frac{E S}{2 L \sqrt{2}} \\
0 & \frac{E S}{2 L \sqrt{2}}+\frac{E S}{2 L \sqrt{2}}+\frac{E S}{L} & \frac{E S}{2 L \sqrt{2}} & -\frac{E S}{2 L \sqrt{2}} & 0 & -\frac{E S}{L} & -\frac{E S}{2 L \sqrt{2}} & -\frac{E S}{2 L \sqrt{2}} \\
-\frac{E S}{2 L \sqrt{2}} & \frac{E S}{2 L \sqrt{2}} & \frac{E S}{2 L \sqrt{2}} & -\frac{E S}{2 L \sqrt{2}} & 0 & 0 & 0 & 0 \\
\frac{E S}{2 L \sqrt{2}} & -\frac{E S}{2 L \sqrt{2}} & -\frac{E S}{2 L \sqrt{2}} & \frac{E S}{2 L \sqrt{2}} & 0 & 0 & 0 & 0 \\
0 & 0 & 0 & 0 & 0 & 0 & 0 & 0 \\
0 & -\frac{E S}{L} & 0 & 0 & 0 & \frac{E S}{L} & 0 & 0 \\
-\frac{E S}{2 L \sqrt{2}} & -\frac{E S}{2 L \sqrt{2}} & 0 & 0 & 0 & 0 & \frac{E S}{2 L \sqrt{2}} & \frac{E S}{2 L \sqrt{2}} \\
-\frac{E S}{2 L \sqrt{2}} & -\frac{E S}{2 L \sqrt{2}} & 0 & 0 & 0 & 0 & \frac{E S}{2 L \sqrt{2}} & \frac{E S}{2 L \sqrt{2}}
\end{array}\right]
$$




\section{Results and Validation}

The results presented in this section are obtained from the finite element computation code developed under MATLAB and, having the architecture of the numerical resolution algorithm presented in Figure 2 and Figure 4. The solving method uses an incremental and iterative method based on minimizing a convergence criterion. Different values of the approximation error of the convergence criterion are used to study its impact on the algorithm used. The MATLAB program is illustrated in the case of the articulated truss shown in Figure 5. A load $\mathrm{F}=35 \mathrm{kN}$ is applied to the structure, the load increment $\mathrm{dF}$ is chosen to be equal to $100 \mathrm{~N}$.

\subsection{Simulation and Validation}

In this paragraph, examples of numerical simulation are presented in order to show the reliability of our algorithm to correctly simulate an elasto-plastic behavior of an articulated truss. Then, the validation is made by comparing with the results obtained from the ABAQUS/CAE computation code.

Tables 2-4 show the main results $\left(\mathrm{N}_{1}, \mathrm{~N}_{2}, \mathrm{~N}_{3}\right.$ : internal forces in each bar element and $\mathrm{V}_{1}$ : vertical displacement of node 1 , see Figure 5) for some load increments obtained from the calculation code developed in MATLAB. The results are presented in each table according to the selected value of the approximation error $\xi$ of the convergence test. The $\xi$ values shown in the tables are: $1,0.01$, and 0.00001 .

The loads chosen as examples in these different tables correspond to the 3 phases of behaviour of the structure: elastic structure (elastic bars), partial plastic structure (bar 2 in the plastic domain), plastic structure (all bars in the plastic domain).

Table 2. Internal forces $\left(\mathrm{N}_{1}, \mathrm{~N}_{2}\right.$ and $\left.\mathrm{N}_{3}\right)$ in the bars and vertical displacement $\mathrm{V}_{1}$ (of node 1) for different loads (approximation error $\xi=1$ ).

\begin{tabular}{ccccc}
\hline \multicolumn{5}{c}{$\mathrm{dF}=100 \mathrm{~N}$ and convergence test $\xi=1$} \\
\hline $\mathrm{F}(\mathrm{N})$ & $\mathrm{N}_{1}=\mathrm{N}_{3}(\mathrm{~N})$ & $\mathrm{N}_{2}(\mathrm{~N})$ & $\begin{array}{c}\text { Displacement } \mathrm{V}_{1} \\
(\mathrm{~mm})\end{array}$ & $\begin{array}{c}\mathrm{N}^{\circ} \text { of } \\
\text { bar-element in } \\
\text { the plastic zone }\end{array}$ \\
\hline 100 & 29.28 & 58.57 & -0.0084 & - \\
500 & 146.44 & 292.89 & -0.0418 & - \\
5000 & 1464.46 & 2928.93 & 0.4184 & - \\
20000 & 5857.86 & $11,715.72$ & 1.6736 & - \\
23600 & 6912.28 & $13,824.55$ & -1.9749 & - \\
24000 & 7029.43 & $14,058.87$ & -2.0084 & 2 \\
24100 & 7085.55 & $14,078.62$ & -2.0244 & 2 \\
24400 & 7293.92 & $14,081.67$ & -2.0840 & 2 \\
30000 & $11,183.47$ & $14,138.43$ & -3.1952 & 1,2 and 3 \\
34200 & $14,087.37$ & $14,199.52$ & -4.3913 & 1,2 and 3 \\
34600 & $14,203.36$ & $14,431.50$ & -8.9327 & \\
\hline
\end{tabular}


Table 3. Internal forces $\left(\mathrm{N}_{1}, \mathrm{~N}_{2}\right.$ and $\left.\mathrm{N}_{3}\right)$ in the bars and vertical displacement $\mathrm{V}_{1}$ (of node 1) for different loads (approximation error $\xi=0.01$ ).

\begin{tabular}{ccccc}
\hline \multicolumn{5}{c}{$\mathrm{dF}=100 \mathrm{~N}$ and convergence test $\xi=0.01$} \\
\hline $\mathrm{F}(\mathrm{N})$ & $\mathrm{N}_{1}=\mathrm{N}_{3}(\mathrm{~N})$ & $\mathrm{N}_{2}(\mathrm{~N})$ & $\begin{array}{c}\text { Displacement } \mathrm{V}_{1} \\
(\mathrm{~mm})\end{array}$ & $\begin{array}{c}\mathrm{N}^{\circ} \text { of } \\
\text { bar-element in } \\
\text { the plastic zone }\end{array}$ \\
\hline 100 & 29.28 & 58.57 & -0.0084 & - \\
500 & 146.44 & 292.89 & -0.0418 & - \\
5000 & 1464.46 & 2928.93 & -0.4184 & - \\
20,000 & 5857.86 & $11,715.72$ & -1.6736 & - \\
23,600 & 6912.28 & $13,824.55$ & -1.9749 & - \\
24,000 & 7029.43 & $14,058.87$ & -2.0084 & 2 \\
24,100 & 7086.16 & $14,078.63$ & -2.0246 & 2 \\
24,400 & 7296.11 & $14,081.70$ & -2.0846 & 2 \\
30,000 & $11,215.07$ & $14,138.89$ & -3.2043 & 1,2 et 3 \\
34,200 & $14,109.89$ & $14,244.57$ & -5.2732 & 1,2 et 3 \\
34,600 & $14,227.04$ & $14,478.86$ & -9.8600 & - \\
\hline
\end{tabular}

Table 4. Internal forces $\left(\mathrm{N}_{1}, \mathrm{~N}_{2}\right.$ and $\left.\mathrm{N}_{3}\right)$ in the bars and vertical displacement $\mathrm{V}_{1}$ (of node 1) for different loads (approximation error $\xi=0.00001$ ).

\begin{tabular}{ccccc}
\hline \multicolumn{5}{c}{$\mathrm{dF}=100 \mathrm{~N}$ and convergence test $\xi=0.00001$} \\
\hline $\mathrm{F}(\mathrm{N})$ & $\mathrm{N}_{1}=\mathrm{N}_{3}(\mathrm{~N})$ & $\mathrm{N}_{2}(\mathrm{~N})$ & $\begin{array}{c}\text { Displacement } \\
\mathrm{V}_{1}(\mathrm{~mm})\end{array}$ & $\begin{array}{c}\mathrm{N}^{\circ} \text { of bar-element } \\
\text { in the plastic } \\
\text { zone }\end{array}$ \\
\hline 100 & 29.28 & 58.5786 & -0.0084 & - \\
500 & 146.44 & 292.8932 & -0.0418 & - \\
5000 & 1464.46 & 2928.93 & -0.4184 & - \\
20,000 & 5857.86 & $11,715.72$ & -1.6736 & - \\
5200 & 1523.04 & 3046.08 & -0.4352 & - \\
23,600 & 6912.28 & $13,824.55$ & -1.9749 & - \\
24,000 & 7029.43 & $14,058.87$ & -2.0084 & 2 \\
24,100 & 7086.17 & $14,078.63$ & -2.0246 & 2 \\
24,400 & 7296.13 & $14,081.70$ & -2.0846 & 2 \\
30,000 & $11,215.48$ & $14,138.90$ & -3.2044 & - \\
34,200 & $14,110.1953$ & $14,245.1695$ & -5.2848 & 1,2 et 3 \\
34,600 & $14,227.3526$ & $14,479.4840$ & -9.8720 & 1,2 et 3 \\
\hline
\end{tabular}

The results presented in Tables 2-4 are compared with the results obtained using the ABAQUS/CAE calculation code. For example, we choose two load cases of $20 \mathrm{kN}$ and $30 \mathrm{kN}$ corresponding to partial and total plasticization phases of the structure. Figure 6 shows the stress states in the truss for the two load cases obtained by ABAQUS. The internal forces in the bars are respectively the couple $\left(\mathrm{N}_{1}=\mathrm{N}_{3}=5858 \mathrm{~N}, \mathrm{~N}_{2}=11715.5 \mathrm{~N}\right)$ and $\left(\mathrm{N}_{1}=\mathrm{N}_{3}=11216 \mathrm{~N}, \mathrm{~N}_{2}=\right.$ $14138.5 \mathrm{~N}$ ) for loads $\mathrm{F}$ of $20 \mathrm{kN}$ and $30 \mathrm{kN}$ respectively. Whatever the load con- 
sidered, the results are quite close to ours (see the corresponding row in Tables 2-4).

Figure 7 shows the evolution of the internal forces as a function of the load. It can be seen that each curve obtained has 3 areas of linearity corresponding to the 3 phases of behaviour of the following truss structure: elastic phase (bars in the elastic), partial plastic phase (bar 2 in the plastic) and complete plasticization phase (bars 1, 2 and 3 in the plastic).

Figure 8 shows the evolution of the vertical displacement $V_{1}$ of node 1 as a function of the load F. As in Figure 7, a tri-linear curve of the displacement $V_{1}$ is observed. An almost exponential increase of the displacement can be seen when all the bars are plasticized. This is explained by the low value of the tangent modulus $\left(\mathrm{E}_{\mathrm{T}} \approx 510 \mathrm{MPa}\right)$ of the bilinear material behaviour law used (see Figure 1).

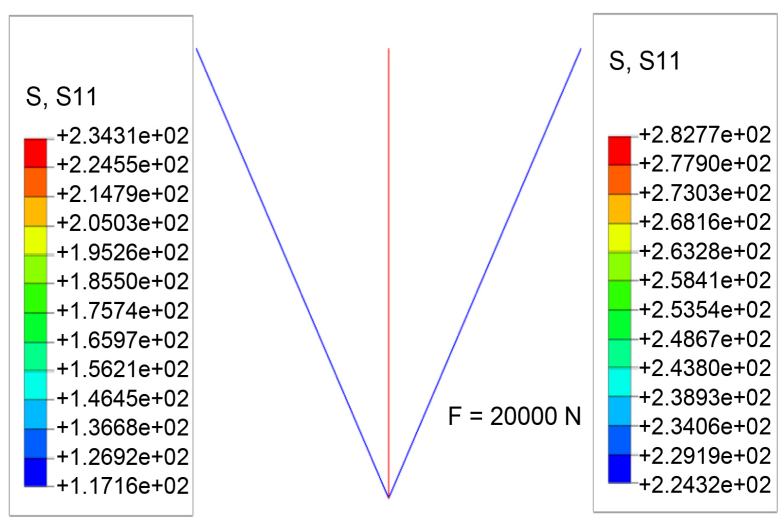

(a)

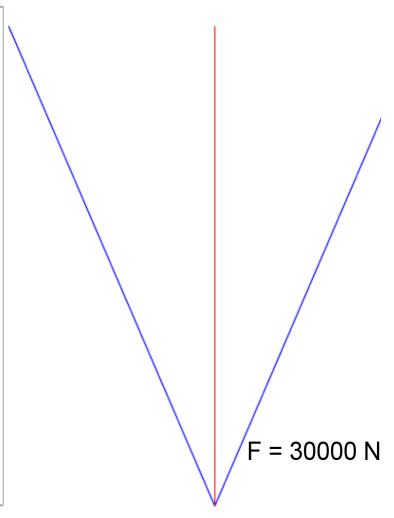

(b)

Figure 6. Stress mapping of the 3-bar truss from ABAQUS, for loads (a) F $=20 \mathrm{kN}$ and (b) $\mathrm{F}=30 \mathrm{kN}$.

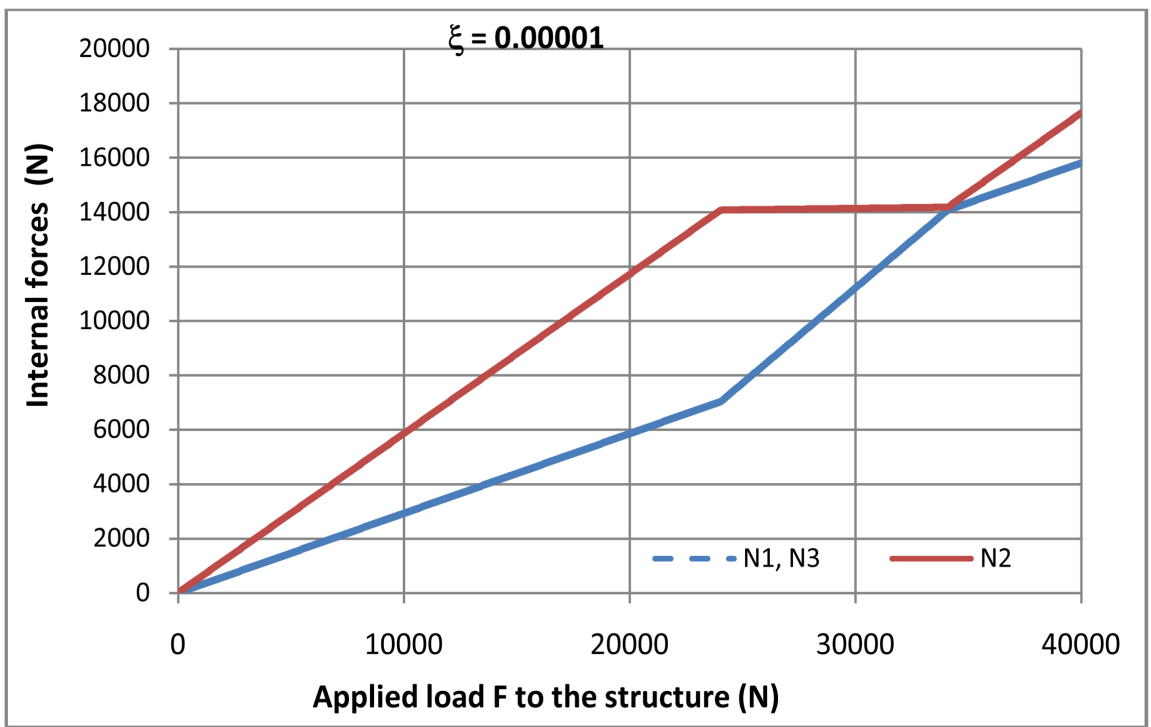

Figure 7. Evolution of the internal forces in the each bar as a function of the load for $\xi=$ 0.00001 . 


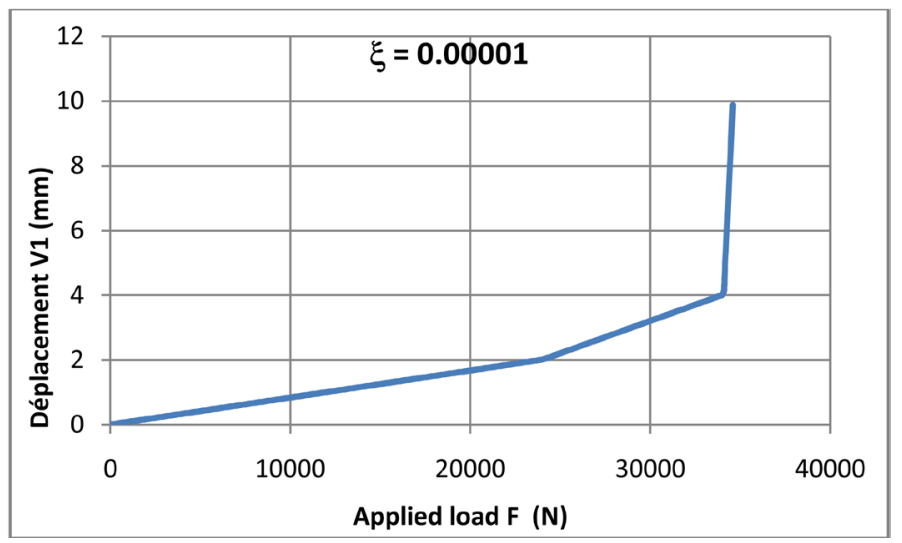

Figure 8. Displacement of the load application point as a function of the load F.
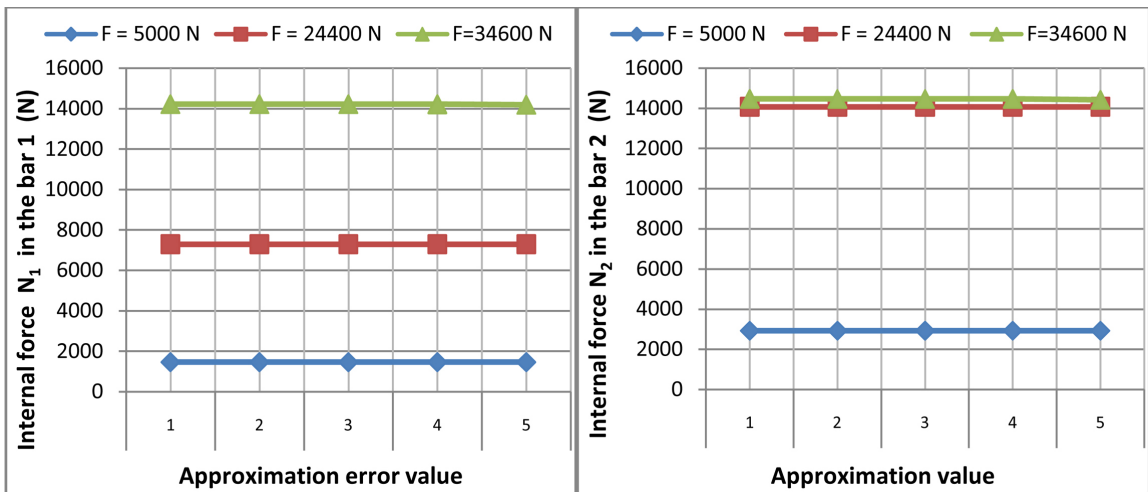

Figure 9. Influence of the approximation error $\xi$ of the convergence test on the internal forces in the bars: (a) bar 1 (b) bar 2.

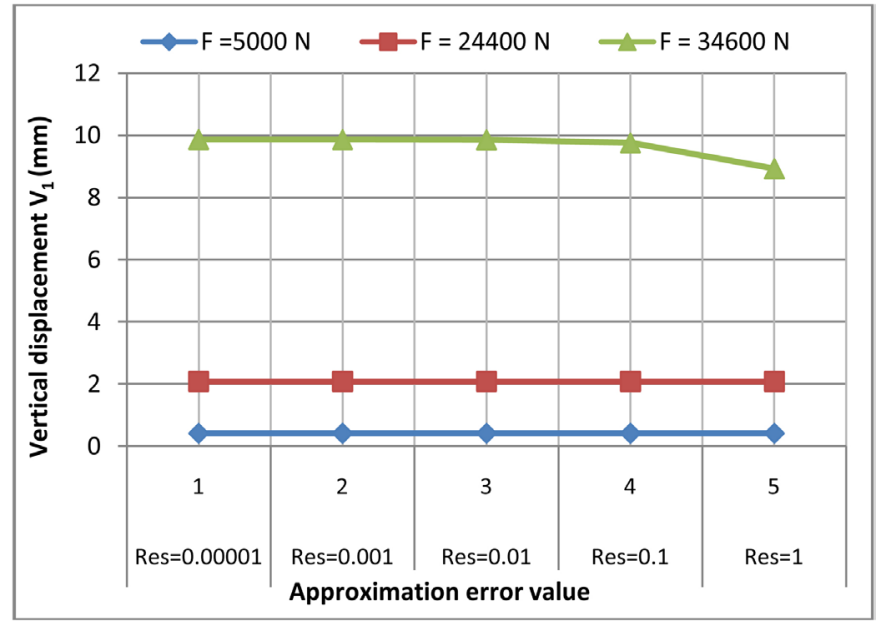

Figure 10. Influences of the approximation error $\xi$ of the convergence test on the vertical displacement $\mathrm{V}_{1}$ of node 1 .

\subsection{Influence of the Value of Approximation Error $\xi$}

In this section, we are interested in the influence of the $\xi$ value on the final result obtained. Figure 9 and Figure 10 illustrate respectively the influence of the $\xi$ 
value on the solution of the internal forces in the bars and the vertical displacement $\mathrm{V}_{1}$ of node 1 . The illustrative load cases are: $5000,24,400$ and $34,600 \mathrm{~N}$ corresponding to the 3 phases of behaviour of the structure. Whatever the load level, it can be seen that the value of $\xi$ has little influence on the final result. Nevertheless, for high loads $(\mathrm{F}=34,600 \mathrm{~N})$, a non-negligible influence of the $\xi$ value on the displacement $V_{1}$ is observed (Figure 10). This weak influence is explained by the bilinear nature of the implemented behaviour law in our study.

\section{Conclusion}

This article presented the development of a FEM calculation code for the simple calculation of an articulated truss structure. A finite element program was developed in the MATLAB environment for a three-bar truss structure. The special feature of the numerical resolution of our computational code is the use of a modified Newton-Raphson projection method, by using a linearized elastoplastic material law. Simulations on a 3-bar articulated truss structure and a comparison with a similar model under ABAQUS have proven the reliability of our approach.

\section{Conflicts of Interest}

The authors declare no conflicts of interest regarding the publication of this paper.

\section{References}

[1] Miyachi, K., Nakamura, S. and Manda, A. (2012) Progressive Collapse Analysis of Steel Truss Bridges and Evaluation of Ductility. Journal of Constructional Steel Research, 78, 192-200. https://doi.org/10.1016/j.jcsr.2012.06.015

[2] Oudin, H. (2009) Introduction à la plasticié. Ecole d'ingénieur. Ecole Centrale de Nantes, 49. https://cel.archives-ouvertes.fr/cel-00483603

[3] Dos Reis, F. and Ganghoffer, J.F. (2014) Homogenized Elastoplastic Response of Repetitive 2D Lattice Truss Materials. Computational Materials Science, 84, 145-155. https://doi.org/10.1016/j.commatsci.2013.11.066

[4] Felipe, T.R.C., Leonel, E.D. and Haach, V.G., (2019) A Comprehensive Ductile Damage Model for 3D Truss Structures. International Journal of Non-Linear Mechanics, 112, 13-24. https://doi.org/10.1016/j.ijnonlinmec.2019.02.010

[5] Kurrer, K.-E. (2018) The History of the Theory of Structures: Searching for Equilibrium. 2nd Edition, John Wiley \& Sons, Berlin, 1212 p. https://doi.org/10.1002/9783433609163

[6] Rebielak, J. (2019) Simple Method of Approximate Calculation of Statically Indeterminate Trusses. International Journal of Computational Methods, 16, Article No. 1840026. https://doi.org/10.1142/S0219876218400261

[7] McKeown, J.J. (1989) The Design of Optimal Trusses via Sequences of Optimal Fixed Displacement Structures. Engineering Optimization, 14, 159-178. https://doi.org/10.1080/03052158908941209

[8] Missoum, S., Gurdal, Z., Hernandez, P. and Guillot, J. (2002) A Displacement Based Optimization for Truss Structures Subjected to Static and Dynamic Constraints. 


\section{AIAA Journal, 40.}

[9] Madah, H. and Amir, O. (2017) Truss Optimization with Buckling Considerations Using Geometrically Nonlinear Beam Modeling. Computers \& Structures, 192, 233-247. https://doi.org/10.1016/j.compstruc.2017.07.023

[10] Subramanian, N. (2008) I-35W Mississippi River Bridge Failure-Is It a Wakeup Call? Indian Concrete Journal, 82, 29-38.

[11] Salem, H.M. and Helmy, H.M. (2014) Numerical Investigation of Collapse of the Minnesota I-35W Bridge. Engineering Structures, 59, 635-645. https://doi.org/10.1016/j.engstruct.2013.11.022

[12] Fan, F., Cao, Z. and Shen, S. (2010) Elasto-Plastic Stability of Single-Layer Reticulated Shells. Thin-Walled Structures, 48, 827-836. https://doi.org/10.1016/j.tws.2010.04.004

[13] Ferrari, R., Cocchetti, G. and Rizzi, E. (2018) Computational Elastoplastic Limit Analysis of the Paderno d'Adda Bridge (Italy, 1889). Archives of Civil and Mechanical Engineering, 18, 291-310. https://doi.org/10.1016/j.acme.2017.05.002

[14] Remache, D., Semaan, M., Rossi, J.M., Pithioux, M. and Milan, J.L. (2020) Application of the Johnson-Cook Plasticity Model in the Finite Element Simulations of the Nanoindentation of the Cortical Bone. Journal of the Mechanical Behavior of Biomedical Materials, 101, Article No. 103426. https://doi.org/10.1016/j.jmbbm.2019.103426

[15] Lemaitre, J., Chaboche, J.L., Benallal, A. and Desmorat, R. (2008) Mécanique des matériaux solides. 3ième edn, Dunod, Paris, 580. 